\title{
HUBUNGAN WAKTU TUNGGU MENUJU OPERASI PENGANGKATAN TUMOR INTRAKRANIAL DENGAN SKALA PERFORMA KARNOFSKY PASCAOPERASI
}

\author{
THE ASSOCIATION BETWEEN WAITING TIME TO INTRACRANIAL TUMOR REMOVAL AND \\ POSTOPERATIVE KARNOFSKY PERFORMANCE SCALE
}

Setyo Widi Nugroho, * Aryandhito Widhi Nugroho, * Renindra Ananda Aman, * Hanif Gordang Tobing*

\section{ABSTRACT}

Introduction: The waiting time to elective intracranial tumor removal surgery in Indonesia is unknown, let alone its association with postoperative functional outcome.

Aim: To identify the waiting time to elective intracranial tumor removal and to analyze its association with poor functional outcome, defined by 3-months postoperative Karnofsky Performance Scale (KPS score) of $\leq 70$.

Methods: This medical record-based retrospective study was performed on intracranial tumor patients underwent elective tumor removal surgery in 2016. Multivariable logistic regression analyses were utilized to determine any significant association between waiting time to elective intracranial tumor removal surgery and poor functional outcome, adjusting for age, sex, preoperative KPS score, pre- and postoperative tumor volume, percentage of tumor removal, tumor histopathology, and grading.

Results: Data were obtained from 191 patients, with histopathology distributions as follows: 49\% meningiomas, $22 \%$ pituitary adenomas, $9 \%$ astrocytomas, 3\% metastatic tumors, 3\% primary central nervous system lymphomas, $2 \%$ oligodendrogliomas, $2 \%$ craniopharyngiomas, and $10 \%$ others. Overall median (min-max) of waiting time to elective intracranial tumor removal surgery was 35 (0-529) days. Significant association between waiting time to elective intracranial tumor removal surgery and poor functional outcome was evident in univariable analysis (OR 1.004), but not in multivariable analysis. The collinearity value of pre-and postoperative tumor volume, percentage of tumor removal with waiting time were, respectively, 5.92; 5.69; and 3.2.

Discussion: There was no significant association between waiting time to elective intracranial tumor removal surgery and poor functional outcome. Strong collinearities were identified between pre- and post-operative tumor volume, percentage of tumor removal and waiting time to elective intracranial tumor removal surgery.

Keywords: functional outcome, intracranial tumor, removal surgery, waiting time

\section{ABSTRAK}

Pendahuluan: Waktu tunggu menuju operasi pengangkatan tumor intrakranial elektif di Indonesia masih belum diketahui, terlebih lagi hubungannya dengan luaran fungsional pascaoperasi.

Tujuan: Mengukur waktu tunggu menuju operasi pengangkatan tumor intrakranial elektif dan menganalisis hubungannya dengan luaran fungsional buruk, yang didefinisikan skor Skala Performa Karnofsky (KPS) 3 bulan pascaoperasi $\leq 70$.

Metode: Studi retrospektif berbasis rekam medis ini dilaksanakan pada pasien tumor intrakranial yang menjalani operasi pengangkatan tumor elektif pada tahun 2016. Analisis regresi logistik multivariabel dipergunakan untuk mencari adanya hubungan bermakna antara waktu tunggu menuju operasi pengangkatan tumor intrakranial elektif dengan luaran fungsional buruk, sambil mempertimbangkan usia, jenis kelamin, skor KPS praoperasi, volume tumor pra- dan pascaoperasi, persentase pengangkatan tumor, patologi. dan grading tumor.

Hasil: Data diperoleh dari 191 pasien, dengan distribusi histopatologi sebagai berikut: 49\% meningioma, $22 \%$ adenoma hipofisis, 9\% astrositoma, 3\% tumor metastatik tumors, 3\% limfoma sistem saraf pusat primer, $2 \%$ oligodendroglioma, $2 \%$ kraniofaringioma, dan 10\% lain-lain. Median (min-maks) waktu tunggu secara umum adalah 35 (0-529) hari. Tampak hubungan bermakna antara waktu tunggu menuju operasi pengangkatan tumor intrakranial elektif dengan luaran fungsional buruk pascaoperasi pada analisis univariabel (RO 1,004), tetapi tidak pada analisis multivariabel. Nilai kolinearitas volume tumor pra-operasi, pascaoperasi dan persentase pengangkatan tumor dengan waktu tunggu masing-masing adalah sebesar 5,92; 5,69; dan 3,2.

Diskusi: Tidak ada hubungan bermakna antara waktu tunggu menuju operasi pengangkatan tumor elektif dengan luaran fungsional buruk pascaoperasi. Terdapat kolinearitas kuat antara waktu tunggu dengan volume tumor pra- dan pascaoperasi serta persentase pengangkatan tumor.

Kata Kunci: luaran fungsional, operasi pengangkatan tumor, tumor intrakranial, waktu tunggu

*Departemen Bedah Saraf, Fakultas Kedokteran Universitas Indonesia, Rumah Sakit Umum Pusat Nasional Dr. Cipto Mangunkusumo. Korespondensi: nug_widi@yahoo.co.id 


\section{PENDAHULUAN}

Pelayanan bedah saraf yang adil dan merata diperlukan untuk melayani warga negara Indonesia yang membutuhkan pertolongan di bidang bedah saraf. ${ }^{1}$ Salah satu indikator layanan bedah saraf adalah waktu tunggu penderita menuju operasi elektif, yang terkait langsung dengan antrian operasi. Parameter ini penting diketahui karena telah terbukti berpengaruh terhadap peningkatan mortalitas dan morbiditas pascaoperasi serta kerugian psiko-sosio-ekonomi. ${ }^{2-3}$ Sejumlah negara di dunia telah melaporkan secara rutin waktu tunggu menuju operasi bedah saraf, seperti Kanada (46,9 hari). ${ }^{4}$ Di Indonesia, belum ada studi yang melaporkan tentang waktu tunggu menuju operasi bedah saraf elektif.

Dari sejumlah penyakit di bidang bedah saraf, tumor intrakranial patut mendapat perhatian khusus karena prevalensi dan insidensnya terus meningkat di dunia dalam 20 tahun terakhir, khususnya pada kelompok usia dewasa. ${ }^{5-6}$ Dampak tumor intrakranial terhadap sistem layanan kesehatan tidak hanya tercermin dari tingginya angka mortalitas penderitanya, tetapi juga tingginya angka morbiditas yang menyebabkan gangguan fungsional dalam kehidupan sehari-hari. $^{7}$

\section{TUJUAN}

Studi ini bertujuan untuk mengukur besaran waktu tunggu menuju operasi pengangkatan tumor elektif pada penderita tumor intrakranial. Lebih lanjut, studi ini juga ingin mengetahui hubungan waktu tunggu ini dengan luaran fungsional 3 bulan pascaoperasi secara umum maupun dalam subtipe tumor.

\section{METODE}

Studi retrospektif ini memanfaatkan sumber data sekunder dari rekam medis penderita tumor intrakranial dewasa yang menjalani operasi pengangkatan tumor elektif di Departemen Bedah Saraf Fakultas Kedokteran Universitas Indonesia (FKUI)/ Rumah Sakit Umum Pusat Nasional dr. Cipto Mangunkusumo (RSUPNCM) tahun 2016. Penderita berusia $\geq 18$ tahun yang diputuskan menjalani operasi elektif untuk mengangkat tumor melalui rapat pengkajian kasus mingguan diikutsertakan dalam studi.
Data yang dikumpulkan meliputi usia, jenis kelamin, waktu tunggu menuju operasi pengangkatan tumor elektif, skor KPS praoperasi, volume tumor pra- dan pascaoperasi, persentase pengangkatan tumor, diagnosis patologi, grading tumor, dan skor KPS pascaoperasi. Waktu tunggu menuju operasi pengangkatan tumor elektif dihitung sejak penderita pertama kali diputuskan menjalani operasi pengangkatan tumor elektif sampai saat operasi dilaksanakan. Skor KPS yang merupakan skala penilaian status fungsional pasien dalam studi ini dikategorikan ke dalam dua kelompok, yaitu $\leq 70$ (dependen, luaran buruk) dan $>70$ (independen, luaran baik). ${ }^{8}$ KPS praoperasi dinilai pada waktu pasien dirawat inap praoperasi, sementara KPS pascaoperasi, luaran studi ini, dinilai 3 bulan pascaoperasi. Volume tumor dihitung menurut magnetic resonance imaging (MRI), setidaknya 6 bulan praoperasi dan 1-3 bulan pascaoperasi menurut metode ellipsoid. ${ }^{9}$ Diagnosis patologi dan grading tumor ditegakkan dari pemeriksaan histopatologik oleh menurut klasifikasi World Health Organization (WHO) terbaru tahun 2016. ${ }^{10}$

Mengenai analisis statistik, uji $\mathrm{T}$ 2-sampel atau Mann-Whitney $\mathrm{U}$ dipergunakan untuk variabel kontinu, sementara uji Chi-square atau Fisher's exact dipergunakan untuk variabel kategori. Uji multikolinearitas dilakukan untuk mencari kolinearitas variabel independen lain dengan waktu tunggu menuju operasi: besaran variance inflation factor (VIF) $>5$ untuk masing-masing variabel menandakan tingginya kolinearitas. ${ }^{11}$ Uji regresi logistik uni- dan multivariabel dilakukan untuk menganalisis hubungan waktu tunggu menuju operasi elektif dengan skor KPS pascaoperasi $\leq 70$, yang digambarkan dengan rasio Odds (RO) dan interval kepercayaan (IK) 95\%, sambil mempertimbangkan usia, jenis kelamin, volume tumor pra- dan pascaoperasi, persentase pengangkatan tumor, diagnosis patologi, grading tumor, dan skor KPS praoperasi sebagai kovariat. Seluruh uji statistik dikerjakan menggunakan perangkat lunak IBM statistical package for the social sciences (SPSS) versi 25 . Nilai $p$ untuk uji dua ekor $<0,05$ bermakna secara statistik. Studi ini telah mendapat persetujuan Komite Etik Penelitian Kesehatan FKUI. 


\section{HASIL}

Karakteristik dasar populasi studi tersaji pada Tabel 1 dan Gambar 1Pada penelitian ini, rerata usia adalah 44,9 tahun dan mayoritas pasien adalah perempuan $(51,8 \%)$. Median (min-maks) waktu tunggu menuju operasi adalah 35 (0-529) hari. Sekitar dua pertiga (67\%) pasien berstatus fungsional dependen sebelum menjalani operasi. Jenis operasi meliputi $77 \%$ kranioektomi dan 23\% transsphenoid. Distribusi subtipe tumor adalah sebagai berikut: $49 \%$ meningioma, $22 \%$ adenoma hipofisis, $9 \%$ astrositoma, $3 \%$ tumor metastatik tumors, $3 \%$ limfoma sistem saraf pusat primer, 2\% oligodendroglioma, 2\% kraniofaringioma, dan 10\% lain-lain. Secara umum, median (min-maks) volume tumor praoperasi adalah $25,2(2,3-97,7) \mathrm{cm}^{3}$, dengan median (min-maks) persentase pengangkatan tumor adalah 74,2 (10$96,3) \%$. Terdapat perbedaan bermakna di antara kedua kelompok skor KPS pascaoperasi dalam hal jenis kelamin, skor KPS praoperasi, dan persentase pengangkatan tumor. diperlihatkan oleh dua variabel independen, volume tumor pra- dan pascaoperasi.

Tabel 3 menyajikan hasil analisis hubungan waktu tunggu menuju operasi dengan luaran skor KPS $\leq 70$ pascaoperasi. Melalui analisis regresi logistik univariabel, ditemukan hubungan bermakna antara sejumlah variabel berikut dengan luaran: jenis kelamin (RO laki-laki adalah 2,03 lipat RO perempuan), persentase pengangkatan tumor (kenaikan 1\% dari persentase pengangkatan tumor memiliki RO 0,98 kali lipat), skor KPS praoperasi (RO skor KPS praoperasi $\leq 70$ adalah 8,53 kali lipat skor KPS praoperasi $>70$ ), dan waktu tunggu (kenaikan 1 hari dari waktu tunggu memiliki RO 1,002 kali lipat). Pada analisis regresi logistik multivariabel, hanya persentase pengangkatan tumor (kenaikan 1\% dari persentase pengangkatan tumor memiliki RO 0,96 kali lipat) dan skor KPS praoperasi (RO skor KPS praoperasi $\leq 70$ adalah 10,75 kali lipat RO skor KPS praoperasi $>70$ ) yang berhubungan bermakna dengan luaran.

Tabel 1. Karakteristik Dasar Sampel Studi dan Stratifikasi Menurut KPS Pascaoperasi (n=191)

\begin{tabular}{|c|c|c|c|c|}
\hline Variabel & $\begin{array}{l}\text { Keseluruhan } \\
\begin{array}{c}(\mathrm{n}=191) \\
\mathbf{n}(\%)\end{array}\end{array}$ & $\begin{array}{c}\text { KPS }<70 \\
(n=73) \\
n(\%)\end{array}$ & $\begin{array}{c}\text { KPS }>70 \\
(n=118) \\
n(\%)\end{array}$ & $\mathbf{p}$ \\
\hline Usia (tahun), Rerata+SD & $44,9+10,9$ & $46,7+11,2$ & $43,9+10,6$ & $0,088^{*}$ \\
\hline Jenis Kelamin & & & & $0,02^{\dagger}$ \\
\hline - Perempuan & $99(51,8)$ & $30(41,1)$ & $69(58,5)$ & \\
\hline - Laki-laki & $92(48,2)$ & $43(58,9)$ & $49(41,5)$ & \\
\hline \multicolumn{5}{|l|}{ Waktu Tunggu (hari) } \\
\hline - Median (Min-maks) & $35(0-529)$ & $53(1-529)$ & $32,5(1-353)$ & $0,099^{\dagger}$ \\
\hline - $>30$ hari & $103(53,9)$ & $42(57,5)$ & $61(51,7)$ & \\
\hline - $0-30$ hari & $88(46,1)$ & $31(42,5)$ & $57(48,3)$ & \\
\hline Skor KPS Praoperasi & & & & $<0,01^{\dagger}$ \\
\hline - Independen $(>70)$ & $63(33)$ & $7(9,6)$ & $56(47,5)$ & \\
\hline - Dependen $(<70)$ & $128(67)$ & $66(90,4)$ & $62(52,5)$ & \\
\hline \multicolumn{5}{|l|}{ Volume Tumor $\left(\mathrm{cm}^{3}\right)$, Median (min-maks) } \\
\hline - Praoperasi & $25,2(2,3-97,7)$ & $25,1(4,3-87,5)$ & $25,4(2,3-97,7)$ & $0,82^{\dagger \dagger}$ \\
\hline - Pascaoperasi & $5,6(0,2-44,2)$ & $8,2(1-32,2)$ & $5,2(0,2-44,2)$ & $0,01^{\dagger}$ \\
\hline Pengangkatan Tumor (\%), Median (min-maks) & $74,2(10-96,3)$ & $72,3(10-96,3)$ & $77,2(32,1-96,2)$ & $0,010^{*}$ \\
\hline
\end{tabular}

*Uji T berpasangan; ${ }^{\dagger}$ Uji Chi-square; ${ }^{\dagger \dagger}$ uji Fisher's exact; KPS: Karnofsky Performance Scale.

Tabel 2 menyajikan hasil uji multikolinearitas variabel independen dengan waktu tunggu operasi pengangkatan tumor intrakranial secara umum. Terlihat kolinearitas kuat dengan waktu tunggu
Tabel 4 menyajikan hasil uji multikolinearitas variabel independen dengan waktu tunggu operasi pengangkatan meningioma, adenoma hipofisis, dan astrositoma. Volume tumor pra- dan pascaoperasi 
Tabel 2. Kolinearitas Variabel Independen Lain dengan Waktu Tunggu Menuju Operasi Pengangkatan Tumor Elektif Secara Umum

\begin{tabular}{lc}
\hline \multicolumn{1}{c}{ Variabel } & VIF \\
\hline Usia & 1,043 \\
Jenis Kelamin, n (\%) & 1,133 \\
Skor KPS Praoperasi & 1,082 \\
Volume Tumor Praoperasi & $5,917^{*}$ \\
Volume Tumor Pascaoperasi & $5,690^{*}$ \\
Persentase Pengangkatan Tumor & 3,213 \\
\hline
\end{tabular}

*VIF>5 menunjukkan kolinearitas kuat; VIF: variance inflation factor.

serta persentase pengangkatan tumor, tampak mempunyai kolinearitas kuat dengan waktu tunggu menuju operasi elektif.

Tabel 5 memperlihatkan analisis multivariabel seluruh variabel independen dengan luaran pada meningioma, adenoma hipofisis, dan astrositoma. Hanya dua variabel independen yang berhubungan bermakna dengan luaran, yaitu skor KPS praoperasi pada meningioma, serta persentase pengangkatan tumor pada meningioma dan adenoma hipofisis.

\section{PEMBAHASAN}

Dalam studi ini, rerata usia penderita $(44,9$ tahun), begitu pula dengan rasio jenis kelamin penderita, sama dengan yang dilaporkan di berbagai studi di benua Asia. ${ }^{12-15}$ Median waktu tunggu menuju operasi pada studi ini (35 hari) lebih cepat daripada temuan di studi oleh Sardana dkk. ${ }^{16}$ Ditinjau dari subtipe tumor, sebuah studi melaporkan median waktu tunggu operasi glioblastoma sebesar 45 hari. ${ }^{17}$ Meskipun waktu tunggu operasi pada studi ini lebih cepat dibandingkan dengan beberapa studi lain, hasil ini memerlukan penelitian lebih lanjut.

Distribusi subtipe tumor dalam studi ini tidak berbeda dengan laporan sejumlah register tumor resmi di dunia, yakni Central Brain Tumor Registry of the United States, the Brain Tumor Registry of Japan, serta register tumor Korea Selatan. ${ }^{15,18-19}$ Penggunaan kontrasepsi hormonal di Indonesia, menurut penulis, secara khusus menjadi penyebab prevalensi meningioma yang tinggi pada perempuan dalam dekade ke-4 kehidupan. Penelitian prospektif berpopulasi besar diperlukan untuk menguji teori ini.

Sejumlah $67 \%$ penderita dalam populasi studi ini didapatkan tidak mampu bekerja atau beraktivitas sama seperti sebelum menderita tumor intrakranial. Menurut Bergo, dkk., status dependensi berperan bermakna terhadap kesintasan penderita pascaoperasi, dan secara khusus terkait dengan status kognisi pasien..$^{20}$ Lebih lanjut, Ediebah. dkk. mengungkapkan bahwa dependensi akan mencetuskan depresi praoperasi yang berlanjut hingga setelah operasi. ${ }^{21}$

Terkait kolinearitas, volume tumor, baik pra- maupun pascaoperasi, berkolinearitas kuat dengan waktu tunggu, dan semakin kuat terlihat di dalam subtipe tumor. Temuan ini memperkuat dugaan bahwa waktu tunggu menuju operasi elektif berbanding lurus dengan volume tumor praoperasi, yang pada akhirnya berbanding lurus dengan kualitas hidup dan status fungsional pascaoperasi. ${ }^{22}$ Pola kolinearitas ini sudah banyak dilaporkan di berbagai studi. Jaaskelainan, dkk. melaporkan doubling time meningioma sebesar 415 hari (grade I), 178 hari (grade II), dan 205 hari (grade III). ${ }^{23}$ Monsalves, dkk. melaporkan doubling time adenoma hipofisis sebesar 747 hari (fungsional) dan 1334 hari (nonfungsional). ${ }^{24}$ Stensjoen, dkk. melaporkan median laju pertumbuhan glioblastoma sebesar 49,6 hari. ${ }^{25}$ Khusus astrositoma, grading WHO berkolinearitas kuat dengan waktu tunggu menuju operasi elektif,

Tabel 3. Analisis Uni- dan Multivariabel dengan Luaran Skor KPS < 70 dalam 3 Bulan Pascaoperasi pada Seluruh Studi Populasi $(n=191)$

\begin{tabular}{|c|c|c|}
\hline Variabel & $\begin{array}{l}\text { Univariabel* } \\
\text { RO (IK 95\%) }\end{array}$ & $\begin{array}{l}\text { Multivariabel }{ }^{\dagger} \\
\text { RO (IK 95\%) }\end{array}$ \\
\hline Usia & $1,02(0,99-1,05)$ & $1,03(0,99-1,07)$ \\
\hline Jenis Kelamin (REF: perempuan) & $2,02(1,12-3,65)$ & $1,19(0,58-2,43)$ \\
\hline Waktu Tunggu & $1,00(1,00-1,01)$ & $1,00(0,99-1,01)$ \\
\hline KPS Praoperasi (REF: >70) & $8,52(3,61-20,10)$ & $10,75(4,11-28,11)$ \\
\hline Persentase Pengangkatan Tumor & $0,98(0,96-0,99)$ & $0,96(0,94-0,98)$ \\
\hline
\end{tabular}

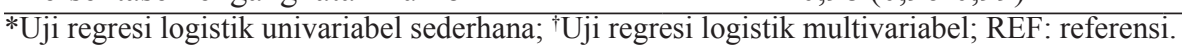


Tabel 4. Kolinearitas Variabel Independen Lain dengan Waktu Tunggu Menuju Operasi Pengangkatan Tumor Elektif pada Meningioma, Adenoma Hipofisis, dan Astrositoma (n=153)

\begin{tabular}{lccc}
\hline \multicolumn{1}{c}{ Variabel } & Meningioma & $\begin{array}{c}\text { Variance Inflation Factor } \\
\text { Adenoma Hipofisis }\end{array}$ & Astrositoma \\
\hline Usia & 1,024 & 1,199 & 3,586 \\
Jenis Kelamin, n (\%) & 1,061 & 1,114 & 1,701 \\
Skor KPS Praoperasi & 1,215 & 1,347 & 1,599 \\
Volume Tumor Praoperasi & 6,090 & 29,922 & 110,536 \\
Volume Tumor Pascaoperasi & 9,703 & 35,110 & 84,211 \\
Persentase Pengangkatan Tumor & 6,262 & 5,146 & 24,323 \\
Grading WHO & 1,060 & $\mathrm{~N}^{*}$ & 7,752 \\
\hline
\end{tabular}

${ }^{*}$ Adenoma hipofisis tidak memiliki grading WHO; WHO: World Health Organization.

Tabel 5. Analisis Multivariabel Variabel Independen dengan Luaran Skor KPS <70 3 Bulan Pascaoperasi pada Kelompok Meningioma, Adenoma Hipofisis, dan Astrositoma (n=153)

\begin{tabular}{lccc}
\hline \multicolumn{1}{c}{ Variabel } & $\begin{array}{c}\text { Meningioma } \\
\text { RO (IK 95\%) }\end{array}$ & $\begin{array}{c}\text { Adenoma hipofisis } \\
\text { RO (IK 95\%) }\end{array}$ & $\begin{array}{c}\text { Astrositoma } \\
\text { RO (IK 95\%) }\end{array}$ \\
\hline Usia & $0,96(0,90-1,02)$ & $0,95(0,86-1,05)$ & $1,16(0,99-1,35)$ \\
Jenis kelamin (REF: perempuan) & $0,72(0,15-3,41)$ & $1,55(0,15-15,82)$ & N/A* \\
Waktu tunggu & $1,01(0,99-1,01)$ & $0,99(0,98-1,02)$ & $1,00(0,99-1,01)$ \\
KPS praoperasi (REF: $>70)$ & $113,62(8,96-1441,74)$ & $7,14(0,71-72,13)$ & $1,42(0,06-34,39)$ \\
Persentase pengangkatan tumor & $0,85(0,77-0,93)$ & $0,84(0,75-0,95)$ & $0,88(0,73-1,06)$ \\
Grading WHO & $2,73(0,40-18,52)$ & N/A** & $1,51(0,27-8,35)$ \\
\hline
\end{tabular}

*Hasil tidak ada karena hanya ada 1 pasien berjenis kelamin perempuan; **Adenoma hipofisis tidak memiliki grading WHO; RO: rasio Odds; IK: interval kepercayaan; REF: referensi; N/A: data tidak tersedia.

sesuai laporan Bogdanska, dkk. (2017). ${ }^{26}$

Secara umum, melalui analisis regresi logistik multivariabel, waktu tunggu tidak ditemukan berhubungan bermakna dengan luaran. Penulis berpendapat bahwa kemaknaan waktu tunggu menuju operasi elektif menjadi tertutupi oleh variabel lain yang berkolinear kuat, yakni volume tumor pra- dan pascaoperasi dan persentase pengangkatan tumor. Meski demikian, penting untuk menjamin bahwa waktu tunggu menuju operasi pengangkatan tumor elektifdicapai sesingkat-singkatnya, sambil menimbang sumber daya yang tersedia. Untuk mencapai hal ini, penulis mengusulkan dilakukannya perbaikan internal di tingkat fasilitas kesehatan (sistem penapisan dini, sistem registrasi, infrastruktur), maupun perbaikan eksternal di tingkat pemerintah (penetapan standar nasional waktu tunggu yang realistis, bukan $<2$ hari; sistem rujukan, dan sistem pembiayaan kesehatan), sehingga pasien terlayani cepat dan tepat. ${ }^{16,27-28}$

Kekuatan studi ini adalah (i) merupakan yang pertama di Indonesia yang meneliti topik ini; (ii) analisis mempertimbangkan usia, jenis kelamin, skor KPS praoperasi, volume tumor, persentase pengangkatan tumor, subtipe histologi tumor dan grading tumor; (iii) dilaksanakan di sebuah rumah sakit umum pusat rujukan nasional, yang menjadi representasi epidemiologi penyakit bedah saraf di Indonesia. Kekurangan studi ini adalah (i) tolak ukur pengukuran waktu tunggu yang dipergunakan dapat menimbulkan bias, karena lamanya gejala dan tanda tumor intrakranial sebelum berobat ke Departemen Bedah Saraf, Rumah Sakit Umum Pusat Nasional dr. Cipto Mangunkusumo tidak diketahui; (ii) skor KPS pradan pascaoperasi didapat melalui wawancara, baik oleh staf maupun residen Departemen Bedah Saraf, Rumah Sakit Umum Pusat Nasional dr. Cipto Mangunkusumo yang berbeda-beda, sehingga terdapat potensi bias antar penilai; (iii) metode pengukuran volume tumor secara ellipsoid mungkin saja tidak setajam metode nonelipsoid/real time/otomatis yang mempertimbangkan seluruh dimensi tumor.

\section{KESIMPULAN}

Tidak ada hubungan bermakna antara waktu tunggu menuju operasi pengangkatan tumor intra- 
kranial elektif dengan skor KPS 3 bulan pascaoperasi.

Kolinearitas kuat teridentifikasi antara waktu tunggu menuju operasi elektif dengan volume tumor pra- dan pascaoperasi serta persentase pengangkatan tumor.

\section{DAFTAR PUSTAKA}

1. Indonesia R. Peraturan Presiden Republik Indonesia Nomor 72 Tahun 2012 Tentang Sistem Kesehatan Nasional. 2012. p. B9.

2. Kelly-Pettersson P, Samuelsson B, Muren O, Unbeck M, Gordon M, Stark A, et al. Waiting time to surgery is correlated with an increased risk of serious adverse events during hospital stay in patients with hipfracture: A cohort study. Int J Nurs Stud. 2017;69:91-7.

3. Nikolova S, Harrison M, Sutton M. The Impact of Waiting Time on Health Gains from Surgery: Evidence from a National Patient-reported Outcome Dataset. Health Econ. 2016;25(8):955-68.

4. Chai C. Q \& A: How long are medical wait times in Canada by province and procedure?2016. Available from: https://globalnews.ca/news/3084366/q-a-howlong-are-medical-wait-times-in-canada-by-provinceand-procedure/.

5. Winn HR YJ. Youman's and Winn's Neurological Surgery. Philadelphia: Elsevier; 2016. 4320 p.

6. Farmanfarma KHK MM, Shahabinia Z, Hassanipour S, Salehiniya H. Brain cancer in the world: an epidemiological review. WCRJ. 2019(6):1356.

7. Global Burden of Disease Cancer C, Fitzmaurice C, Allen C, Barber RM, Barregard L, Bhutta ZA, et al. Global, Regional, and National Cancer Incidence, Mortality, Years of Life Lost, Years Lived With Disability, and Disability-Adjusted Life-years for 32 Cancer Groups, 1990 to 2015: A Systematic Analysis for the Global Burden of Disease Study. JAMA oncology. 2017;3(4):524-48.

8. Blakeley JO, Coons SJ, Corboy JR, Kline Leidy N, Mendoza TR, Wefel JS. Clinical outcome assessment in malignant glioma trials: measuring signs, symptoms, and functional limitations. Neuro Oncol. 2016;18 Suppl 2:ii13-ii20.

9. Sreenivasan SA, Madhugiri VS, Sasidharan GM, Kumar RV. Measuring glioma volumes: A comparison of linear measurement based formulae with the manual image segmentation technique. J Cancer Res Ther. 2016;12(1):161-8.

10. Louis DN, Perry A, Reifenberger G, von Deimling A, Figarella-Branger D, Cavenee WK, et al. The 2016 World Health Organization Classification of Tumors of the Central Nervous System: a summary. Acta neuropathol. 2016;131(6):803-20.

11. Marcoulides KM, Raykov T. Evaluation of Variance Inflation Factors in Regression Models Using Latent
Variable Modeling Methods. Educ Psychol Meas. 2019;79(5):874-82.

12. Salehpour F, Mirzaei F, Meshkini A, Parsay S, Salehi S, Asl MMB. Trends in Primary Brain Tumors: A 5-Year Retrospective Histologically Confirmed Study in Tabriz, Iran, 2011-2016. Asian J Neurosurg. 2019;14(2):427-31.

13. Almutrafi A, Bashawry Y, AlShakweer W, Al-Harbi M, Altwairgi A, Al-Dandan S. The Epidemiology of Primary Central Nervous System Tumors at the National Neurologic Institute in Saudi Arabia: A TenYear Single-Institution Study. J Cancer Epidemiol. 2020;2020:1429615.

14. Mondal S PR, Pal S, Biswas B, Banerjee A, Bhattacharyya D. Clinicopathological pattern of brain tumors: A 3-year study in a tertiary care hospital in India. Clin Cancer Investig J. 2016;5:437-40.

15. Shibui S. [Transition in the data of brain tumor registry based on the reports of Brain Tumor Registry of Japan]. Nihon Rinsho. 2016;74 Suppl 7:51-8.

16. Sardana SR GS, Sharma DK, Vij A, Kale SS Analysis of waiting time for elective surgical procedures in neurosurgery department at a tertiary care teaching hospital in NCT, India. Int J Res Med Sci. 2017;5(10):4538-44.

17. Flanigan PM, Jahangiri A, Kuang R, Truong A, Choi S, Chou A, et al. Improved Survival with Decreased Wait Time to Surgery in Glioblastoma Patients Presenting with Seizure. Neurosurg. 2017;81(5):82433.

18. Ostrom QT, Cioffi G, Gittleman H, Patil N, Waite $\mathrm{K}$, Kruchko C, et al. CBTRUS Statistical Report: Primary Brain and Other Central Nervous System Tumors Diagnosed in the United States in 2012-2016. Neuro Oncol. 2019;21(Suppl 5):v1-v100.

19. Dho YS, Jung KW, Ha J, Seo Y, Park CK, Won YJ, et al. An Updated Nationwide Epidemiology of Primary Brain Tumors in Republic of Korea, 2013. Brain Tumor Res Treat. 2017;5(1):16-23.

20. Bergo E, Lombardi G, Guglieri I, Capovilla E, Pambuku A, Zagone V. Neurocognitive functions and health-related quality of life in glioblastoma patients: a concise review of the literature. Eur J Cancer Care. 2019;28(1):e12410.

21. Ediebah DE, Reijneveld JC, Taphoorn MJ, Coens C, Zikos E, Aaronson NK, et al. Impact of neurocognitive deficits on patient-proxy agreement regarding healthrelated quality of life in low-grade glioma patients. Qual Life Res. 2017;26(4):869-80.

22. Galhom AE, Madawi AA, Ellabban MM. Surgical outcomes and predictors of complication in elderly patients with meningiomas. Egypt J Neurol Psychiatr Neurosurg. 2018;54(1):3. 
23. Fountain DM, Soon WC, Matys T, Guilfoyle MR, Kirollos R, Santarius T. Volumetric growth rates of meningioma and its correlation with histological diagnosis and clinical outcome: a systematic review. Acta Neurochir. 2017;159(3):435-45.

24. Monsalves E, Larjani S, Loyola Godoy B, Juraschka K, Carvalho F, Kucharczyk W, et al. Growth patterns of pituitary adenomas and histopathological correlates. $\mathrm{J}$ Clin Endrocrinol Metab. 2014;99(4):1330-8.

25. Stensjoen AL, Solheim O, Kvistad KA, Haberg AK, Salvesen O, Berntsen EM. Growth dynamics of untreated glioblastomas in vivo. Neuro Oncol. 2015;17(10):1402-11.
26. Bogdanska MU, Bodnar M, Piotrowska MJ, Murek $\mathrm{M}$, Schucht P, Beck J, et al. A mathematical model describes the malignant transformation of low grade gliomas: Prognostic implications. PloS one. 2017;12(8):e0179999.

27. Peraturan Menteri Kesehatan Republik Indonesia No.3 Tahun 2020, (2020).

28. Indonesia MKR. Keputusan Menteri Kesehatan Republik Indonesia Nomor 129/Menkes/SK/II/2008 Tentang Standar Pelayanan Minimal Rumah Sakit. 2008. 